Verheul, W., Sanders, A., Bensing, J. The effects of physicians' affect-oriented communication style and raising expectations on analogue patients' anxiety, affect and expectancies. Patient Education and Counseling: 2010, 80(3), 300-306

\begin{tabular}{|l|l|}
\hline Postprint Version & 1.0 \\
\hline Journal website & http://linkinghub.elsevier.com/retrieve/pii/S0738-3991(10)00379-4 \\
\hline Pubmed link & http://www.ncbi.nlm.nih.gov/pubmed/20638815 \\
\hline DOI & $10.1016 /$ j.pec.2010.06.017 \\
\hline
\end{tabular}

This is a NIVEL certified Post Print, more info at http://www.nivel.eu

\title{
The effects of physicians' affect-oriented communication style and raising expectations on analogue patients' anxiety, affect and expectancies
}

\author{
William Verheul ${ }^{\text {A }},{ }^{*}$, ARIËTTE SANDERS ${ }^{\text {B }}$, JOZIEN BENSING ${ }^{\text {A C }}$ \\ ${ }^{a}$ NIVEL (Netherlands Institute for Health Services Research), Utrecht, The Netherlands \\ b Julius Center for Health Sciences and Primary Care, University Medical Center Utrecht, Utrecht, The \\ Netherlands \\ ${ }^{\mathrm{c}}$ Faculty of Social and Behavioral Science, Utrecht University, The Netherlands
}

\begin{abstract}
Objective Patients' affect and expectancies can set off placebo effects and thus impact patients' health. We assessed the relative effects of physicians' affect-oriented communication style and raising expectations on patients' affective state and outcome expectancies.

Method Thirty healthy women presented severe menstrual pain in a scripted consultation with a general practitioner (GP). In a $2 \times 2$ randomized controlled trial, the GP communicated in a warm, empathic or cold, formal way and raised positive or uncertain expectations. Effects on subjects' state anxiety, affective state and outcome expectancies were assessed.

Results Only warm, empathic communication combined with positive expectations led to a significant and relevant decrease in state anxiety. Subjects' positive and negative affects were influenced by GPs affect-oriented communication style. Negative affect and outcome expectancies are influenced by GP suggestions about outcomes.

Conclusion Manipulations in physicians' affect-oriented and expectancy-related communication can have a large impact on patients' affective state and outcome expectations. A combination of a warm, empathic communication style and raising positive expectations resulted in optimal subject outcomes.

Practice implications Physicians should take into account that communicating in warm, empathic way combined with raising positive expectations seems to lead to the most favorable effects on patients' state anxiety and outcome expectancies.
\end{abstract}

\section{BACKGROUND}

Several review studies have demonstrated that clinical communication can influence patient health outcomes [1], [2] and [3]. However, in most of these studies, communication is used as a container concept and usually the mechanisms through which communication might influence outcomes are not specified [3]. Therefore, instead of using communication as a 'container concept', we need to (1) define potential mechanisms which can explain the influence of specific communication behaviors on patient outcomes, (2) operationalize these mechanisms in observable behaviors, and (3) systematically vary these behaviors in controlled experiments [4] and [5]. 
Verheul, W., Sanders, A., Bensing, J. The effects of physicians' affect-oriented communication style and raising expectations on analogue patients' anxiety, affect and expectancies. Patient Education and Counseling: 2010, 80(3), 300-306

\subsection{The placebo effect}

Potential mechanisms that might explain the observed effects of communication on patient health can be found in the literature on placebo effects in healthcare [6]. Placebo effects are the genuine psychological or physiological effects, which are attributable to receiving a substance or undergoing a procedure, but are not due to the inherent powers of that substance or procedure [7]. Placebo effect theories are thus based on the assumption that the effect of medical treatment is not only dependent on the inherent characteristics of the treatment, but also of the entire psychological, social and cultural context that surrounds the treatment [8]. Mechanisms that play a role in the placebo effect are conditioned learning processes, positive or negative expectancies, and the reduction of negative affect [9]. This paper focuses on the relative influence of physician's manipulation of expectancies and affect on patients' health related cognitions and emotions.

\subsection{Expectancy manipulation}

If a healthcare provider raises expectations considering the effects of a treatment or the course of an illness, then this can lead to psychological and physiological effects that alter patients' health status. For example, Thomas [10] found in his study "Is there any point in being positive" that a positive, reassuring physician communication style lead to better health outcomes two weeks after the consultation in comparison to non-positive consultations. However, in a replication study these results could not be reproduced [11]. In both these studies a 'positive consultation' was only defined in terms of the physician giving a clear diagnosis combined with a positive outcome expectation (versus an unclear diagnosis with raising uncertain outcome expectations), without specific attention for affect-oriented communication. Nevertheless, it is clear that information about medical procedures and treatment and the management of illness can influence self-efficacy expectations and outcome expectations. In turn, these expectations can lead to positive and negative health outcomes [2] and [12].

\subsection{Manipulation of affect}

Evoking positive and reducing negative feelings in patients is naturally desirable from an ethical perspective, but patients' affective state can also play an important role for patients' health status [5], for instance by its capability to influence the immune system [13], wound healing [13], pain [14] and the sympathetic nervous system [15].

\subsection{Using communication to set off placebo effect mechanisms}

To establish the role of communication in "placebo effects" on patients' health, we need to study how healthcare provider communication might set off the discussed mechanisms and how this fits in with the current knowledge from research on patient-provider interaction. Physician-patient communication has to fulfill different criteria in order to be successful. This connects to what Engel [16] called the patient's double need: one to know and understand and one to feel known and understood. For both needs, physician-patient communication has been shown to play an important role [17]. The need to know and understand is a cognitive need served by the transfer of information, such as the doctor telling the patient what is happening with their body and what they can expect, i.e. raising expectations. The second need is an emotional need for which affective communication is important. Affective communication is communication targeted at establishing a good therapeutic relationship between physician and patient. Examples are eye contact, empathic statements and leaving room for the patient to tell their story [17], [18], [19], [20], [21], [22], [23], [24] and [25].

Despite of the growing knowledge on the underpinnings of the placebo effect, it remains unclear how raising expectations and affect-oriented communication are influencing patient outcomes. Furthermore, those two factors most probably interact: a suggestion only causes an expectation, if the patient believes the physician. To that purpose, the patient needs to trust the physician [26] and affect-oriented communication plays an important role in creating trust [27]. This means that affect-oriented communication can enhance the expectation elicited by healthcare providers. Affect-oriented communication has also direct effects on reduction of negative affect, as it can reduce anxiety [28] and can increase feeling emotionally supported [29].

In the literature the distinction between affect-oriented communication and raising expectations is often not made and as such their relative contribution yet unclear. Therefore, our study focused on disentangling these components of communication and aimed to assess the separate and combined effects of raising patients' expectations and affect-oriented communication on several patient outcomes. Our hypotheses 
Verheul, W., Sanders, A., Bensing, J. The effects of physicians' affect-oriented communication style and raising expectations on analogue patients' anxiety, affect and expectancies. Patient Education and Counseling: 2010, 80(3), 300-306

were: (1) A physician's positive affect-oriented communication will lead to less self-reported anxiety and negative affect and to more positive affect in patients than when a physician has a negative affect-oriented communication style. (2) A physician's verbal suggestion of positive outcome will lead to more positive expectancies and positive affect in patients and to less self-reported anxiety and negative affect compared to the condition where a physician suggests an uncertain outcome.

(3) A physician's affect-oriented communication style will interact with the verbal suggestions of outcome: positive affect-oriented communication will increase effects of verbal suggestions, while negative affect-oriented communication will reduce the effect of the suggestions.

\section{METHODS}

\subsection{Design}

The study has an experimental design using videotaped medical consultations in which two communication elements (expectancies and affect) were manipulated in a $2 \times 2$ design (see Table 1). Thirty healthy subjects took part as analogue patients [23], [24] and [28] in a role-played consultation with a GP. These analogue patients presented symptoms according to a simple script. The GP communicated in either a warm and empathic or a cold and formal manner and raised positive or negative expectancies considering treatment outcome. The GP was trained to perform the above communication styles by extensive practicing under supervision of a drama teacher and the researcher to attain a high degree of standardisation and reality. Group allocation was randomized and blind to everyone (analogue patients and involved researchers), except for the GP. Randomization and blinding took place by using sealed envelopes; the GP opened an envelope containing the assigned condition a few minutes before the consultation. After participation in the consultation and a 15-min break, during which the subjects filled in questionnaires and watched a neutral/relaxing video (fishes in an aquarium), subjects were again exposed to the same consultation by watching the video of their consultation. Patients completed questionnaires before and after the consultation and after watching their consultation on video. We used role-played consultations because this methodology offers better experimental control than real clinical consultations: in this way noise through heterogeneity of consultations could be prevented, while retaining a high ecological validity [30]. Also, using negative affective communication and suggesting uncertain outcomes randomly would often be unethical in real consultations. The video watching procedure is also presumed to be a valid proxy of actual communication as humans have the empathic ability to experience situations from the viewpoint of a person they watch [5], [31] and [32].

\section{[TABLE 1]}

\subsection{Sample}

Thirty women were recruited by information leaflets at various locations (e.g. stores, waiting rooms at health centres, university, and sport centres). The study was conducted at a GP's practice. Inclusion criteria for analogue patients were being female, between 18 and 45 years of age, being able to have an unaided conversation in Dutch and self-reported experience with period pain. Only women were included in this study to avoid large sample sizes or confounding gender effects, as gender effects are generally large in physician-patient communication [19], [24], [25], [33], [34] and [35]. Menstrual pain was chosen because it is a very common symptom among women in a reproductive age [36], [37] and [38], which means that most women can easily imagine themselves in the scripted situation. Women who knew the GP were excluded to prevent influence from previous experiences. Analogue patients received $€ 40$ in gift vouchers for their participation.

\subsection{Experimental conditions}

\subsubsection{Affect manipulation}

In the positive affective communication condition, the GP opened with a friendly, inviting welcome, directed her gaze and body posture mainly to the analogue patient and added empathic statements to the 
Verheul, W., Sanders, A., Bensing, J. The effects of physicians' affect-oriented communication style and raising expectations on analogue patients' anxiety, affect and expectancies. Patient Education and Counseling: 2010, 80(3), 300-306

interview. (This must be quite difficult for you/hearing your story, I noticed that this problem put quite a strain on you/I understand how you must be feeling.) In the negative affective communication conditions, the GP opened with a formal and cold welcome, directed her gaze and body posture mainly away from the patient and left out empathic statements.

\subsubsection{Expectancy manipulation}

In the positive expectancy condition, the GP praised the effectiveness of non-steroidal anti-inflammatory drugs (NSAIDs) in reducing menstrual pain [39] in the conclusion phase of the interview. In the uncertain expectancy conditions, the GP mentioned the NSAIDs as well, but commented that their effect on the presented menstrual pain is uncertain and it is not sure that the NSAIDs will help much. In Table 1 the four experimental groups are shown.

\subsection{Instruments}

\subsubsection{Measures of affect}

State anxiety was measured with the short STAI-state with a total score which can range from 10 to 40 [40] and [41]. State anxiety was chosen because of its proven responsiveness to different types of medical communication [28]. Analogue patients' positive and negative affects were measured with PANAS [42], which measures these two concepts on separate largely independent scales of ten items each. Scale scores can range from 5 up to 50 .

\subsubsection{Measures for patients' expectations}

Outcome expectations were measured with three relevant items on ten-point scales from the brief Illness Perception Questionnaire (IPQ) [43] in order to assess changes in cognitions about the (simulated) complaint. These items concerned expected continuation of pain, expected control over pain and expected treatment effect.

\subsubsection{Validity and manipulation check}

Additionally, we asked two questions to subjects about how realistic they perceived the simulation: "Were you able to feel as if you were taking part in a real consultation?" and "Do you think this conversation resembles a real consultation with a GP?" These questions were answered on a five-point scale. A score of five indicated that subjects were perfectly able to feel as if in a real consultation and that they perceived the consultation perfectly realistic.

Furthermore, a research assistant who was blinded to the conditions watched the videos of the consultations and coded the GP's friendliness and the extent to which the GP raised positive or uncertain expectations on a five-point scale in order to check if the conditions were successfully applied.

\subsection{Procedures}

The study protocol was approved by the Medical Ethical Committee of Utrecht University. Subjects were sent information about the study and gave their informed consent.

In the experiment analogue patients were welcomed by the researcher and informed about the study procedures. Analogue patients then received a short script on the nature of their complaints which they were asked to present to the GP. This script was also already presented to subjects in the information letter. The script asked the analogue patient to simulate visiting a GP for severe menstrual pain ([7] on a scale of [10]), which has a significant disabling influence on their daily activities and social contacts for five days in every menstrual cycle. As this was a simulation, this does not need to reflect their own medical history, although all analogue patients were familiar with menstrual pain. Analogue patients were then asked to actively try and feel as if they were actually visiting a GP according to the script from then on. Analogue patients filled in self-report measures. These preparations took about $20 \mathrm{~min}$. Subsequently, a female GP entered the consultation room and performed a 10-min consultation according to one of described conditions. After concluding the consultation, the GP left the room. Again the analogue patient filled in questionnaires (10 min). Then analogue patients watched the neutral video for $5 \mathrm{~min}$. Consequently analogue patients completed the pre-consultation measures $(5 \mathrm{~min})$. Analogue patients were explicitly asked to imagine being in the consultation again when watching the video of the consultation. The video was projected life-sized 
Verheul, W., Sanders, A., Bensing, J. The effects of physicians' affect-oriented communication style and raising expectations on analogue patients' anxiety, affect and expectancies. Patient Education and Counseling: 2010, 80(3), 300-306

on a white wall in front of the analogue patient. Afterwards, measurement procedures were repeated in exactly the same way as after participation in the consultation. After completing the questionnaires, the analogue patients were debriefed.

\subsection{Data analysis}

Data were imported into SPSS Statistics 17. Outcomes were assessed in a general linear model (GLM) by assessing main effects of affect and expectancy manipulation and their interaction on post-consultation measures. In these analyses, we controlled for their pre-consultation baseline. The interaction term was removed from the model when not statistically significant to assess main effects without interaction. Mean differences and standard deviations between pre- and post-consultation scores are presented together with the t-statistic for main and interaction effects. t-Statistics were evaluated in one-tailed tests (only the hypothesized direction) at a $\mathrm{p}$-value of 0.05 .

\section{RESULTS}

\subsection{Background and general statistics}

Analogue patients had a mean age of 25 years, their educational level was intermediate to high. Their actual mean experienced menstrual pain on a VAS scale was $35 \%$ (with $100 \%$ indicating most pain imaginable) for pain intensity and $38 \%$ for pain unpleasantness. They indicated that they found it easy to imagine they were taking part in a real consultation (mean 3.78 out of 5). This measure correlated with the VAS scores (both $r=0.5, p<0.01$ ) Subjects also thought the consultation closely resembled a real consultation with a GP (3.8 out of 5). This measure did not significantly correlate with the VAS scores $(\mathrm{r}=0.05, \mathrm{p}=0.8$ for pain intensity, $\mathrm{r}=-0.05, \mathrm{p}=0.8$ for pain unpleasantness). The manipulation check showed that the conditions were successfully applied. Subjects' age, educational level or VAS scores did not significantly differ across experimental groups. Means and standard deviations of all scores are presented in Table 2 .

\section{[TABLE 2]}

\subsection{Affect measures}

Analogue patients' state anxiety after the consultation was lower when the GP combined communicating in a warm and empathic manner with suggesting a positive treatment outcome compared to all other conditions. Fig. 1 shows that application of individual factors (only suggesting a positive treatment outcome or only warm, empathic communication) do not lead to a relevant decrease of state anxiety when participating in the consultation (see Fig. 1). The GLM reveals a main effect for the affect manipulation and an interaction effect (Table 3). When watching the video, the decrease in state anxiety was also largest when the GP raised positive expectations while having a positive affective communication style, however only a significant main effect for affective communication was found (see Fig. 2 and Table 3).

\section{[FIGURE 1]}

\section{[TABLE 3]}

[figure 2] For analogue patients' post-consultation negative affect, we found the same pattern, with a marginally significant interaction effect for the combination of affective communication and positive verbal expectancies $(\mathrm{p}=0.05)$ : see Table 3 .

Analogue patients' positive affect was highest after a consultation when the GP had a warm and empathic communication style (main effect, $p=0.023$ ): see Table 3 . Positive and negative affects were not significantly influenced when watching the video, albeit the same patterns were visible as when participating.

\subsection{Outcome expectations}

Analogue patients expected a shorter continuation of their symptoms, more control on their pain and higher treatment effectiveness when the GP suggested a positive treatment outcome rather than an uncertain outcome. No significant main effect for affective communication was found (although a trend was found 
Verheul, W., Sanders, A., Bensing, J. The effects of physicians' affect-oriented communication style and raising expectations on analogue patients' anxiety, affect and expectancies. Patient Education and Counseling: 2010, 80(3), 300-306

for treatment expectations), an interaction effect was also not present (see Fig. 3 and Table 3). For the expected continuation of symptoms variable, a main effect for affective communication style was significant: positive affective communication style lead patients to expect that their pain would last shorter $(\mathrm{t}=1.72, \mathrm{p}=0.049)$, but only when the non-significant interaction term was included in the model. This indicates that this outcome is different in only one group (only positive affective communication style combined with suggesting positive treatment outcome shows a relevant decrease in expected continuation of pain: see Table 2). When watching the video of the consultation, generally the same patterns were found: there was a significant effect for expectation on all expectancy-outcome measures. However, there was also an effect for affective communication and an interaction effect for expected treatment effect: see Fig. 4 (and marginally significant effects for continuation of pain for these factors: see Table 3). Again the positive affect combined with positive expectations leads to the best results (Table 2).

\section{[FIGURE 3]}

\section{[FIGURE 4]}

\section{DISCUSSION AND CONCLUSION}

Departing from hypotheses derived from theory on the placebo effect, this study made a focused attempt to disentangle the separate and combined effects of a physician's affect-oriented communication style and raising of treatment outcome expectations on analogue patients' anxiety, affective state and outcome expectancies.

\subsection{Discussion}

\subsubsection{The effects of varying physician's affect-oriented communication style and raising expectations}

We expected that a physician's raising of positive expectations and positive affect-oriented communication would lead to more favorable effects on patient's state anxiety, affective state, as well as treatment and outcome expectancies then when a physician does not raise positive expectations and has a negative affectoriented communication style. We expected the largest beneficial effects when positive expectations were combined with a positive affective communication style. Several predicted effects on patient anxiety, positive and negative affect and expectancies were found. For almost every outcome a warm and empathic communication style combined with statements about a positive treatment outcome lead quite clearly to the best results on patient outcomes.

From these results we can deduct that, in order to provide optimum patient care, it is not enough for physicians to generate only positive expectations, because if a physician does so while communicating in a cold manner, patients' anxiety will not decrease and patients' will have less trust in a positive outcome. However, communicating in a warm and empathic way is also insufficient for optimum results. The combination of a warm and empathic communication style and raising positive expectations leads to less anxiety and more positive expectancies in patients.

\subsubsection{Disentangling affect-oriented communication style and raising positive expectation}

This study allowed us to discern several quite large effects of both GP's suggestions and affective communication style. The results considering expectations are in line with Thomas' inspiring study "Is there any point in being positive". However in this study, affect-oriented communication was not part of the communication being manipulated [10]. This might be a reason that a replication study [11], in contrast with Thomas, did not find an effect of GPs raising positive expectations. Thomas was a "rather charismatic GP who may have had a placebo effect influence on his patients" [11] and he performed all the consultations in his study. In Knipschild et al.'s replication study, several different GPs were used, who on average might have had lesser affective communication skills than Thomas. It seems important that, when researching either the effects of affective communication or of expectancies, it is important to take both into account, as their separate and combined effects are both very relevant to patient outcomes.

\subsubsection{Strengths and limitations}


Verheul, W., Sanders, A., Bensing, J. The effects of physicians' affect-oriented communication style and raising expectations on analogue patients' anxiety, affect and expectancies. Patient Education and Counseling: 2010, 80(3), 300-306

The strengths of this study are its focused hypotheses, the experimental approach with high control over conditions and the separate assessment of the effect of affect-oriented communication and raising expectations. A limitation of this study is its focus on a relatively non-severe health problem only existing for women. This means that caution should be exercised with generalizing the results, as long as results are not replicated in studies with other health problems and male subjects.

\subsubsection{Methodological reflections}

The high experimental control due to our role-playing approach ensured the experimental control over the conditions (the GP's communicative behavior), however, this might have impacted the external validity of our results. Because of ethical considerations, we could not perform this experiment in real, clinical situations. We do believe that we adequately ensured this validity by using participants who were familiar with symptoms they presented and by letting the consultation take place in an actual GP practice with a real GP. Although the physician's communications style was scripted, the communication to which patients were exposed was realistic and such variation, including the negative affective communication style, can be found in clinical practice [44].

By exposing analogue patients to a simulated medical consultation in two ways (by letting them participate in a role-played consultation and by letting them watch this consultation on video), we have some indication about the robustness of the results within analogue patients. In general the same pattern was found. However, the two differing methods might account for some differences. It seems that the affective impact of watching video is somewhat lower in comparison to participating in a medical consultation. In our study, this might also be a habituation effect, since the two methods were repeated relatively short after each other. Because of this repeated exposure, patients could also draw on their own memory, therefore the validity of this video watching approach should be examined when using this approach on subjects who did not participate in the consultation that is watched.

\subsection{Conclusion}

In conclusion, this study shows that simple manipulations of affect-oriented and instrumental physician communication can have a large impact on patients' affective state and treatment outcome expectancies. The combination of raising positive expectations and communicating in a warm and empathic manner seems to lead to the most favorable effects on patients' state anxiety, affective state and outcome expectancies.

\subsection{Practice implications}

Healthcare providers must realize that affective communication style and outcome expectations are important factors that modulate the impact of therapeutic interventions on health outcomes. This study suggests that a physicians' communication style has a relevant effect on patients' state anxiety and on outcome expectations which, according to theory on the placebo effect [5], may have a direct impact on patients' health and treatment outcomes.

\section{CONFLICT OF INTEREST STATEMENT}

The authors have no conflict of interest.

\section{FUNDING}

This study was funded by the Spinoza Prize awarded to Professor Jozien Bensing, PhD by the Dutch Research Council (NWO).

\section{ACKNOWLEDGEMENTS}

We would like to thank the women who participated in this study. We also would like to thank the Patient Provider Interaction group (the Dutch chapter of $\mathrm{EACH}$ ) for commenting on an earlier version of this paper and Lenja Witlox for video-coding. 
Verheul, W., Sanders, A., Bensing, J. The effects of physicians' affect-oriented communication style and raising expectations on analogue patients' anxiety, affect and expectancies. Patient Education and Counseling: 2010, 80(3), 300-306

\section{TABLE 1}

Table 1

Experimental groups.

\begin{tabular}{|c|c|c|c|}
\hline Group 1 & Group 2 & Group 3 & Group 4 \\
\hline $\begin{array}{l}\text { Negative affect: cold and formal } \\
\text { communication }\end{array}$ & $\begin{array}{l}\text { Negative affect: cold and formal } \\
\text { communication }\end{array}$ & $\begin{array}{l}\text { Positive affect: warm and } \\
\text { empathic communication }\end{array}$ & $\begin{array}{l}\text { Positive affect: warm and empathic } \\
\text { communication }\end{array}$ \\
\hline $\begin{array}{l}\text { Uncertain outcome: uncertain expectations } \\
\text { were raised }\end{array}$ & $\begin{array}{l}\text { Positive outcome: positive } \\
\text { expectations were raised }\end{array}$ & $\begin{array}{l}\text { Uncertain outcome: } \\
\text { uncertain expectations } \\
\text { were raised }\end{array}$ & $\begin{array}{l}\text { Positive outcome: positive expectancy } \\
\text { were raised }\end{array}$ \\
\hline
\end{tabular}

\section{TABLE 2}

Table 2

Means and standard deviations before and after the medical consultation across conditions.

\begin{tabular}{|c|c|c|c|c|c|c|c|c|c|c|c|c|c|c|c|c|}
\hline & \multicolumn{4}{|c|}{ Group 1: Aff-/Exp- } & \multicolumn{4}{|c|}{ Group2: Aff-/Exp+ } & \multicolumn{4}{|c|}{ Group 3: Aff+/Exp- } & \multicolumn{4}{|c|}{ Group 4: Aff+/Exp+ } \\
\hline & \multicolumn{2}{|l|}{ Pre } & \multicolumn{2}{|l|}{ Post } & \multicolumn{2}{|l|}{ Pre } & \multicolumn{2}{|l|}{ Post } & \multicolumn{2}{|l|}{ Pre } & \multicolumn{2}{|l|}{ Post } & \multicolumn{2}{|l|}{ Pre } & \multicolumn{2}{|l|}{ Post } \\
\hline & $\bar{x}$ & $(\mathrm{SD})$ & $\bar{x}$ & $(\mathrm{SD})$ & $\bar{x}$ & $(\mathrm{SD})$ & $\bar{x}$ & $(\mathrm{SD})$ & $\bar{x}$ & $(\mathrm{SD})$ & $\bar{x}$ & $(\mathrm{SD})$ & $\bar{x}$ & $(\mathrm{SD})$ & $\bar{x}$ & $(\mathrm{SD})$ \\
\hline \multicolumn{17}{|l|}{ Participation in consultation } \\
\hline STAI-state anxiety & 18.5 & (3.8) & 19.1 & $(4.1)$ & 21.8 & $(5.5)$ & 21.1 & $(5.0)$ & 24.6 & (4.7) & 24.0 & $(4.2)$ & 22.6 & (7.1) & 16.1 & (3.8) \\
\hline PANAS-negative affect & 12.5 & $(2.1)$ & 14.5 & $(5.0)$ & 20.3 & $(8.5)$ & 19.0 & $(6.2)$ & 22.1 & $(7.5)$ & 20.9 & $(6.5)$ & 22.9 & $(11.6)$ & 15.6 & (7.5) \\
\hline PANAS-positive affect & 29.1 & (4.6) & 26.6 & (5.4) & 28.9 & $(5.0)$ & 29.4 & (6.6) & 29.9 & (5.4) & 28.1 & $(5.8)$ & 29.1 & $(5.8)$ & 31.7 & $(5.3)$ \\
\hline IPQ-expected continuation of pain & 6.0 & $(2.1)$ & 7.0 & $(2.1)$ & 7.1 & $(1.0)$ & 7.6 & (1.3) & 7.0 & $(0.8)$ & 6.4 & (1.3) & 7.4 & (1.6) & 5.6 & (2.1) \\
\hline IPQ-expected controllability of pain & 3.5 & $(2.0)$ & 3.9 & (1.6) & 3.3 & (1.9) & 4.3 & (2.7) & 2.7 & (1.8) & 6.9 & (1.6) & 2.9 & $(2.1)$ & 5.3 & $(2.8)$ \\
\hline IPQ-expected treatment effect & 6.4 & (1.7) & 3.5 & (2.0) & 4.9 & $(2.0)$ & 3.9 & $(2.2)$ & 6.4 & (1.7) & 6.1 & (1.6) & 5.6 & $(2.2)$ & 7.4 & $(0.8)$ \\
\hline \multicolumn{17}{|l|}{ Watching video of consultation } \\
\hline STAI-state anxiety & 18.9 & (3.5) & 18.7 & $(4.3)$ & 21.4 & $(4.1)$ & 18.8 & $(4.8)$ & 22.8 & $(4.8)$ & 21.2 & $(4.5)$ & 22.3 & $(6.2)$ & 17.1 & $(4.7)$ \\
\hline PANAS-negative affect & 13.7 & (5.9) & 14.4 & (7.2) & 18.4 & (6.5) & 15.4 & (5.7) & 19.6 & $(9.0)$ & 15.8 & $(6.2)$ & 20.4 & (13.3) & 14.6 & $(8.6)$ \\
\hline PANAS-positive affect & 27.7 & $(5.5)$ & 26.3 & (3.9) & 28.0 & $(6.0)$ & 30.0 & (5.9) & 27.3 & (6.0) & 28.2 & $(8.4)$ & 28.7 & $(5.3)$ & 28.4 & $(6.5)$ \\
\hline IPQ-expected continuation of pain & 5.9 & $(2.0)$ & 6.4 & (1.9) & 7.4 & $(0.7)$ & 7.5 & $(1.2)$ & 6.5 & (1.9) & 6.2 & $(1.7)$ & 7.1 & $(1.2)$ & 5.0 & $(2.2)$ \\
\hline IPQ-expected controllability of pain & 4.1 & (1.6) & 3.7 & (1.4) & 4.6 & $(1.7)$ & 4.3 & (2.3) & 4.5 & (2.7) & 7.3 & (1.4) & 3.0 & (1.5) & 5.7 & (2.5) \\
\hline IPQ-expected treatment effect & 5.0 & (1.5) & 4.1 & (1.1) & 4.8 & $(1.3)$ & 3.9 & $(2.0)$ & 5.5 & $(1.8)$ & 4.8 & (3.4) & 5.4 & (1.9) & 7.6 & (1.0) \\
\hline
\end{tabular}

Aff $-=$ cold and formal communication; Aff $+=$ warm and empathic communication; Exp+= raising positive outcome expectations; Exp-=raising negative outcome expectations; $\bar{x}=$ mean; $\mathrm{SD}=$ standard deviation of the mean. 
Verheul, W., Sanders, A., Bensing, J. The effects of physicians' affect-oriented communication style and raising expectations on analogue patients' anxiety, affect and expectancies. Patient Education and Counseling:

\section{FIGURE 1}

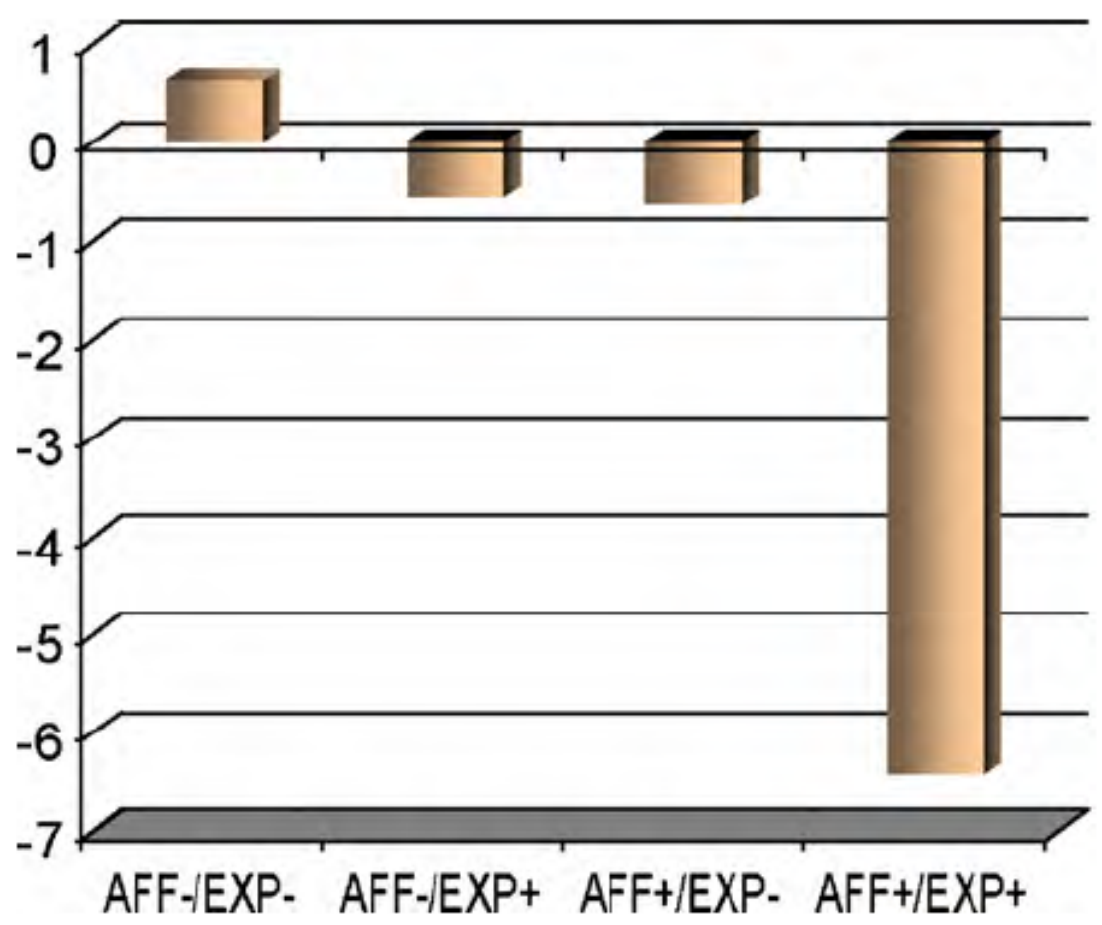

Fig. 1. Change in state anxiety (participation). Aff- $=$ cold and formal communication; Aff $+=$ warm and empathic communication; Exp $+=$ raising positive outcome expectations; Exp- = raising negative outcome. 
Verheul, W., Sanders, A., Bensing, J. The effects of physicians' affect-oriented communication style and raising expectations on analogue patients' anxiety, affect and expectancies. Patient Education and Counseling: 2010, 80(3), 300-306

\section{FIGURE 2}

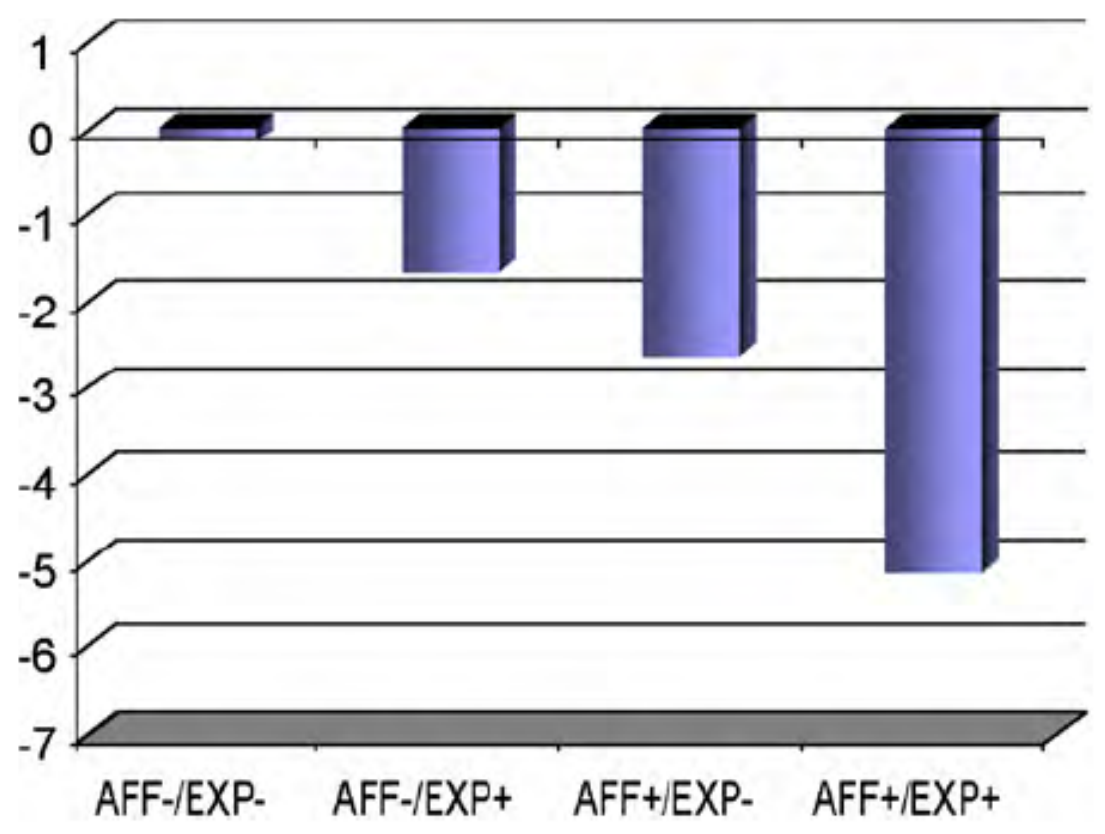

Fig. 2. Change in state anxiety (watching video). Aff $-=$ cold and formal communication; $A f f+=$ warm and empathic communication; Exp $+=$ raising positive outcome expectations; Exp $-=$ raising negative outcome. 
Verheul, W., Sanders, A., Bensing, J. The effects of physicians' affect-oriented communication style and raising expectations on analogue patients' anxiety, affect and expectancies. Patient Education and Counseling:

\section{FIGURE 3}

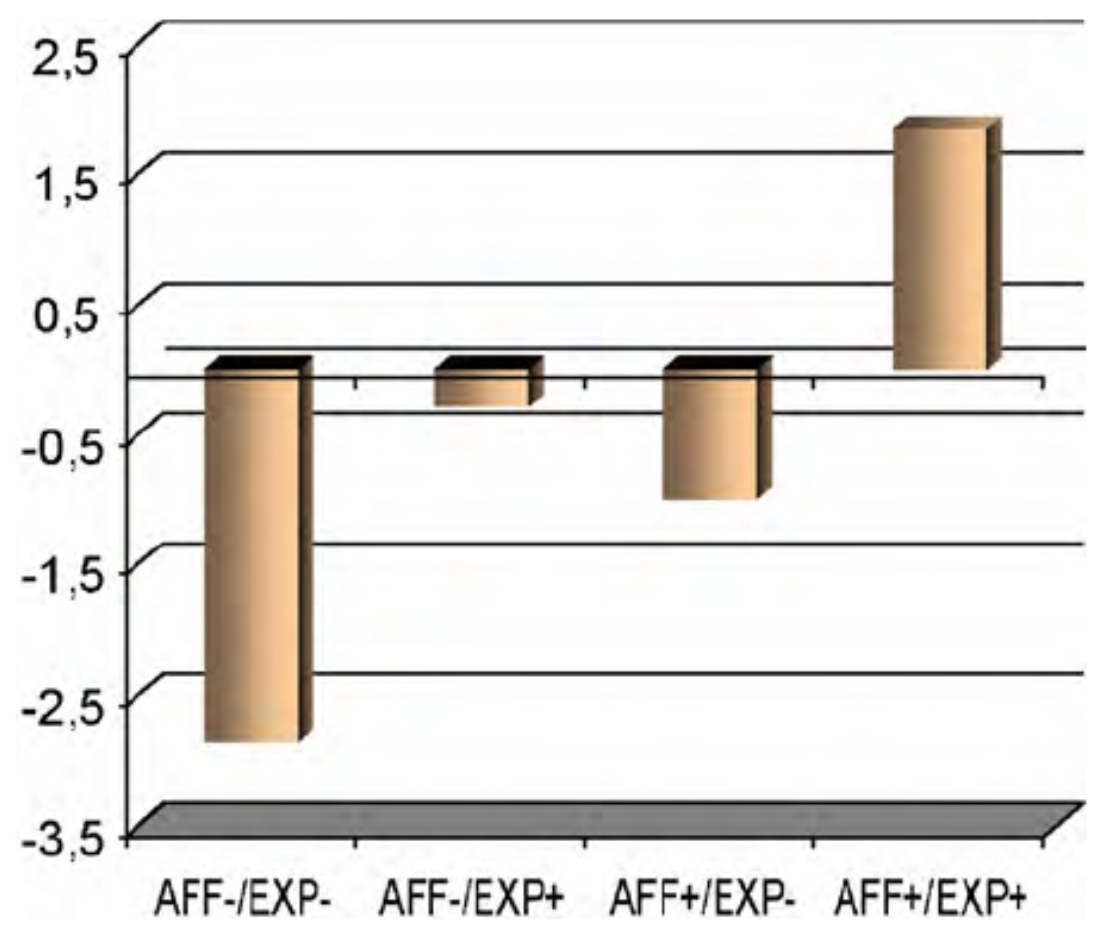

Fig. 3. Change in expected treatment effect (participation). Aff $-=$ cold and formal communication; $A f f+=$ warm and empathic communication; Exp $+=$ raising positive outcome expectations; Exp- - raising negative outcome. 
Verheul, W., Sanders, A., Bensing, J. The effects of physicians' affect-oriented communication style and raising expectations on analogue patients' anxiety, affect and expectancies. Patient Education and Counseling: 2010, 80(3), 300-306

\section{FIGURE 4}

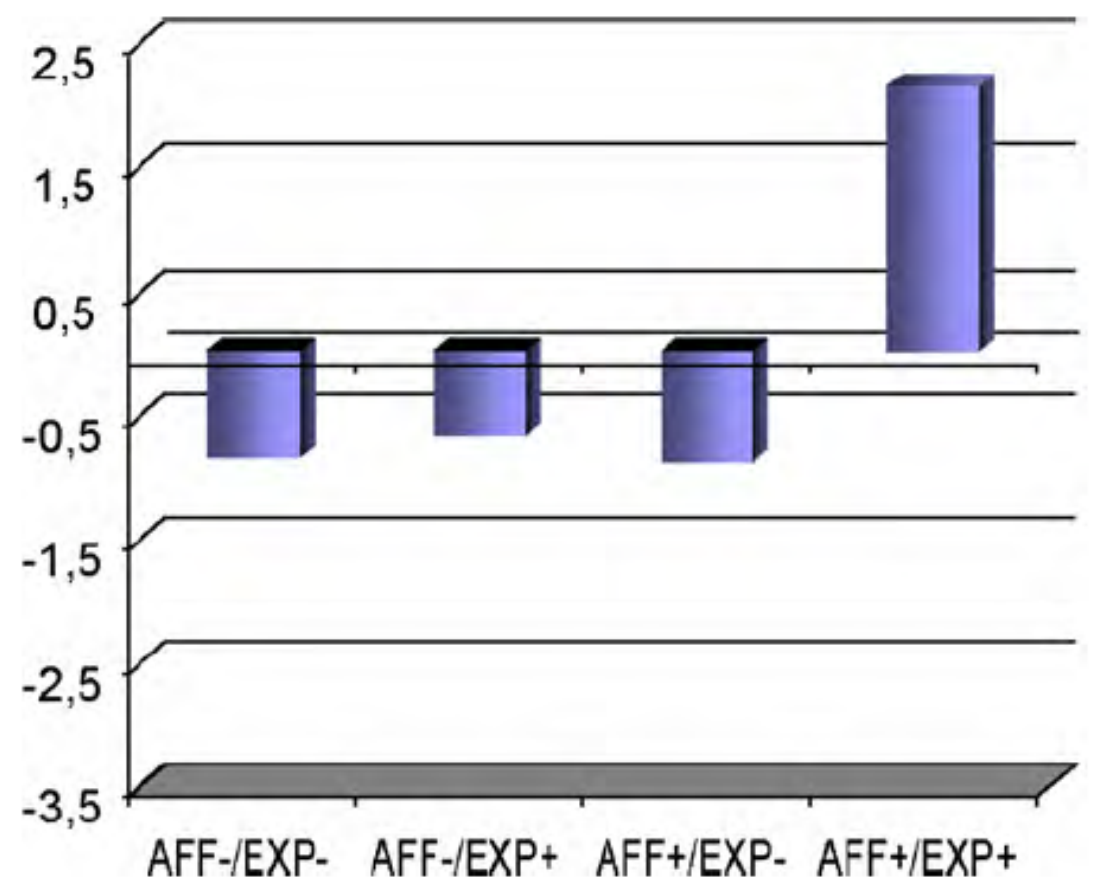

Fig. 4. Change in expected treatment effect (watching video). Aff - = cold and formal communication; $\mathrm{Aff}+=$ warm and empathic communication; Exp $+=$ raising positive outcome expectations; Exp-= raising negative outcome. 
Verheul, W., Sanders, A., Bensing, J. The effects of physicians' affect-oriented communication style and raising expectations on analogue patients' anxiety, affect and expectancies. Patient Education and Counseling: 2010, 80(3), 300-306

\section{REFERENCES}

[1] Di Blasi Z, Harkness E, Ernst E, Georgiou A, Kleijnen J. Influence of context effects on health outcomes: a systematic review. Lancet 2001;357:757-62.

[2] Crow R, Gage H, Hampson S, Hart J, Kimber A, Thomas H. The role of expectancies in the placebo effect and their use in the delivery of health care: a systematic review. Health Technol Assess 1999;3:196.

[3] Griffin SJ, Kinmonth AL, Veltmn MWM, Gillard S, Grant J, Steward M. Effect on health-related outcomes of interventions to alter the interaction between patients and practitioners: a systematic review of trials. Ann Fam Med 2004;2:595-608.

[4] de Haes $\mathrm{H}$, Bensing $\mathrm{J}$. Endpoints in medical communication research, proposing a framework of functions and outcomes. Patient Educ Couns 2009;74:287-94.

[5] Bensing JM, Verheul W. The silent healer: the role of communication in placebo effects. Patient Educ Couns; this issue.

[6] Kong J, Kaptchuk TJ, Polich G, Kirsch I, Gollub RL. Placebo analgesia: findings from brain imaging studies and emerging hypotheses. Rev Neurosci 2007;18:173-90.

[7] Stewart-Williams S, Podd J. The placebo effect: dissolving the expectancy versus conditioning debate. Psychol Bull 2004;130:324-40.

[8] Shapiro AK, Shapiro E. The placebo: is it much ado about nothing? In: Harrington A, editor. The placebo effect: an interdisciplinary exploration.

Cambridge, MA: Harvard University Press; 1997.

[9] Dulmen AMv, Bensing JM. The effect of context in health care: a programming study. Den Haag: RGO; 2001.

[10] Thomas KB. General practice consultations: is there any point in being positive? Br Med J (Clin Res Ed) 1987;294:1200-2.

[11] Knipschild P, Arntz A. Pain patients in a randomized trial did not show a significant effect of a positive consultation. J Clin Epidemiol 2005;58:708-13.

[12] Price DD, Finniss DG, Benedetti F. A comprehensive review of the placebo effect: recent advances and current thought. Annu Rev Psychol 2008;59: 565-90.

[13] Cohen S, Frank E, Doyle WJ, Skoner DP, Rabin BS, Gwaltney Jr JM. Types of stressors that increase susceptibility to the common cold in healthy adults.

Health Psychol 1998;17:214-23.

[14] Klossika I, Flor H, Kamping S, Bleichhardt G, Trautmann N, Treede R, et al.

Emotional modulation of pain: a clinical perspective. Pain 2006;124:264-8.

[15] Drummond PD, Finch PM, Skipworth S, Blockey P. Pain increases during sympathetic arousal in patients with complex regional pain syndrome. Neurology 2001;57:1296-303.

[16] Engel GL. How much longer must medicine's science be bound by a seventeenth century world view. In: White K, editor. The task of medicine: dialogue at Wickenburg. Menlo Park: The Henry Kaiser Foundation; 1988. p. 113-6.

[17] Bensing JM, Dronkers J. Instrumental and affective aspects of physician behavior. Med Care 1992;30:283-98.

[18] Bensing JM, Tromp F, van Dulmen S, van den Brink-Muinen A, Verheul W, Schellevis FG. Shifts in doctor-patient communication between 1986 and 2002: a study of videotaped general practice consultations with hypertension patients. BMC Fam Pract 2006;7:62.

[19] Brink-Muinen A, van Dulmen S, Messerli-Rohrbach V, Bensing J. Do gender-dyads have different communication patterns? A comparative study in western-European general practices. Patient Educ Couns 2002;48: 253-64.

[20] Hall JA, Roter DL, Katz NR. Task versus socioemotional behaviors in physicians.

Med Care 1987;25:399-412.

[21] Roter D, Larson S. The roter interaction analysis system (RIAS): utility and flexibility for analysis of medical interactions. Patient Educ Couns 2002;46:243-51.

[22] Roter DL, Frankel RM, Hall JA, Sluyter D. The expression of emotion through nonverbal behavior in medical visits. Mechanisms and outcomes. J Gen Intern Med 2006;21(Suppl. 1):S28-34.

[23] Roter DL, Hall JA, Katz NR. Relations between physicians' behaviors and analogue patients' satisfaction, recall, and impressions. Med Care 1987;25: 437-51.

[24] Schmid Mast M, Hall JA, Roter DL. Disentangling physician sex and physician communication style: their effects on patient satisfaction in a virtual medical visit. Patient Educ Couns 2007;68:16-22.

[25] van den Brink-Muinen A. The role of gender in healthcare communication.

Patient Educ Couns 2002;48:199-200. 
Verheul, W., Sanders, A., Bensing, J. The effects of physicians' affect-oriented communication style and raising expectations on analogue patients' anxiety, affect and expectancies. Patient Education and Counseling: 2010, 80(3), 300-306

[26] Hall MA, Dugan E, Zheng B, Mishra AK. Trust in physicians and medical institutions: what is it, can it be measured, and does it matter? Milbank Q 2001;79:613-39.

[27] Thom DH. Physician behaviors that predict patient trust. J Fam Pract 2001;50:323-8.

[28] Fogarty LA, Curbow BA, Wingard JR, McDonnell K, Somerfield MR. Can 40 seconds of compassion reduce patient anxiety? J Clin Oncol 1999;17:371.

[29] Ben Sira Z. Affective and instrumental components in the physician-patient relationship: an additional dimension of interaction theory. J Health Soc Behav 1980;21:170-80.

[30] Roberts NA, Tsai JL, Coan JA. Emotion elicitation using dyadic interaction tasks.

In: Coan JS, Allen JJB, editors. Handbook of emotion elicitation and assessment.

Oxford: Oxford University Press; 2007. p. 106-23.

[31] Rottenberg J, Ray RD, Gross JJ. Emotion elicitation using films. In: Coan JS, Allen JL, editors. Handbook of emotion elicitation and assessment. Oxford: Oxford University Press; 2007. p. 9-28.

[32] Lamm C, Nusbaum HC, Meltzoff AN, Decety J. What are you feeling? Using functional magnetic resonance imaging to assess the modulation of sensory and affective responses during empathy for pain. PLOS ONE 2007;2:e1292.

[33] Roter D, Lipkin Jr M, Korsgaard A. Sex differences in patients' and physicians' communicationduring primary caremedical visits.MedCare1991;29:1083-93.

[34] Hall JA, Irish JT, Roter DL, Ehrlich CM, Miller LH. Satisfaction, gender, and communication in medical visits. Med Care 1994;32:1216-31.

[35] Hall JA, Roter DL. Patient gender and communication with physicians: results of a community-based study. Womens Health 1995;1:77-95.

[36] Harlow SD, Park M. A longitudinal study of risk factors for the occurrence, duration and severity of menstrual cramps in a cohort of college women. Br J Obstet Gynaecol 1996;103:1134-42.

[37] Sternfeld B, Swindle R, Chawla A, Long S, Kennedy S. Severity of premenstrual symptoms in a health maintenance organization population. Obstet Gynecol 2002;99:1014-24.

[38] Jamieson DJ, Steege JF. The prevalence of dysmenorrhea, dyspareunia, pelvic pain, and irritable bowel syndrome in primary care practices. Obstet Gynecol 1996;87:55-8.

[39] French L. Dysmenorrhea. Am Fam Physician 2005;71:285-91.

[40] Spielberger CD, Gorsuch RL, Lushene RE. STAI manual for the state-trait anxiety inventory. Palo Alto: Consulting Psychologists Press; 1970.

[41] van der Bij AK, de Weerd S, Cikot RJ, Steegers EA, Braspenning JC. Validation of the Dutch short form of the state scale of the Spielberger state-trait anxiety inventory: considerations for usage in screening outcomes. Community Genet 2003;6:84-7.

[42] Watson D, Clark LA, Tellegen A. Development and validation of brief measures of positive and negative affect: the PANAS scales. J Pers Soc Psychol 1988;54:1063-70.

[43] Broadbent E, Petrie KJ, Main J, Weinman J. The brief illness perception questionnaire. J Psychosom Res 2006;60:631-7.

[44] Wofford MM, Wofford JL, Bothra J, Kendrick SB, Smith A, Lichstein PR. Patient complaints about physician behaviors: a qualitative study. Acad Med 2004;79: 134-8. 